\title{
How do family medicine residents choose an anticoagulation regimen for patients with nonvalvular atrial fibrillation?
}

\author{
Payam Yazdan-Ashoori ${ }^{1}$, Zardasht Oqab ${ }^{2}$, William F. Mclntyre ${ }^{3}$, Kieran L. Quinn ${ }^{1}$, Erik van Oosten ${ }^{4}$, \\ Wilma M. Hopman ${ }^{5}$ and Ádrian Baranchuk ${ }^{6}$ \\ ${ }^{1}$ Department of Medicine, University of Toronto, Toronto, Ontario, Canada \\ ${ }^{2}$ Section of Cardiology, University of Calgary, Calgary, Alberta, Canada \\ ${ }^{3}$ Section of Cardiology, University of Manitoba, Winnipeg, Manitoba, Canada \\ ${ }^{4}$ Department of Medicine, Western University, London, Ontario, Canada \\ ${ }^{5}$ Department of Community Health and Epidemiology, Queen's University, Kingston, Ontario, Canada \\ ${ }^{6}$ Division of Cardiology, Queen's University, Kingston, Ontario, Canada
}

\begin{abstract}
Aim: To examine the choices Canadian family medicine residents make for oral anticoagulation $(\mathrm{OAC})$ for patients with nonvalvular atrial fibrillation $(\mathrm{AF})$. Background: $A F$ increases the risk of strokes. An important consideration in AF management is risk stratification for stroke and prescription of appropriate OAC. Family physicians provide the vast majority of OAC prescriptions. Methods: We administered a survey to residents in multiple Canadian family medicine training programmes. Questions explored the experiences and attitudes towards risk stratification and choices of OAC when presented with standardized clinical scenarios. In each scenario, a novel oral anticoagulant (NOAC) would be the preferred treatment according to the contemporary Canadian and European guidelines. Findings: A total of 247 residents participated in the survey. Most used the congestive heart failure, hypertension, age $\geq 75$, diabetes mellitus, stroke or TIA ( 2 points) ( $81 \%$ ) and congestive heart failure, hypertension, age $\geq 75$ ( 2 points) or age 65-74 (1 point), diabetes mellitus, stroke or TIA, vascular disease including peripheral arterial disease, myocardial infarction, or aortic plaque, sex (female) (67\%) risk stratification schemes while the preferred bleeding risk stratification scheme was hypertension, abnormal liver or renal function, stroke, bleeding, labile international normalized ratio, elderly (age $\geq 65$ ), drugs or alcohol $(84 \%)$. In the clinical scenarios, residents generally preferred warfarin in favour of NOACs, independent of training level. Residents ranked the risk of adverse events and the cost to the patient as their most and least important consideration when prescribing OAC, respectively. Therefore in patients with nonvalvular AF, Canadian family medicine residents prefer warfarin in comparison with NOACs despite the latest Canadian and European guideline recommendations. This knowledge gap may be enhanced by multiple factors, including a sometimes magnified fear of adverse events and a rapidly changing landscape in stroke prophylaxis.
\end{abstract}

Key words: anticoagulants; atrial fibrillation; family practice; guideline adherence; internship and residency

Received 19 July 2016; revised 22 January 2017; accepted 17 March 2017;

first published online 3 May 2017

Correspondence to: Dr William F. McIntyre, Chief Cardiology Resident, University of Manitoba, St. Boniface Hospital, 409 Taché Ave., Y3009 Winnipeg, Manitoba, Canada, R2H 2A6. Email: wfmcintyre@gmail.com

\section{Introduction}

Atrial fibrillation (AF) is the most common cardiac arrhythmia, with an estimated lifetime risk of one in four and is an important risk factor for ischaemic

(C) Cambridge University Press 2017 
stroke (Go et al., 2001; Albers et al., 2004; Andrade et al., 2014). A cornerstone of AF management is clinical risk stratification for stroke and bleeding along with subsequent prescription of appropriate oral anticoagulation (OAC). Family physicians provide $\sim 85 \%$ of all OAC prescriptions and the ongoing therapeutic relationship they share with patients is ideal for delivering a patient-centred approach to balancing the risks and benefits associated with OAC (King et al., 2002; Weitz et al., 2015).

Warfarin, a vitamin $\mathrm{K}$ antagonist (VKA), is effective in preventing strokes with a relative risk reduction of $64 \%$ (Hart et al., 2007). However, warfarin has many food and drug interactions (Wells et al., 1994), is associated with adverse effects leading to hospitalization (Pirmohamed et al., 2004), requires frequent laboratory monitoring and may be outside of therapeutic range up to $72 \%$ of the time (Jones et al., 2005). The novel or non-VKA oral anticoagulants (NOAC) were developed to address warfarin's shortcomings. The direct thrombin inhibitor dabigatran (Connolly et al., 2009) and factor Xa inhibitors rivaroxaban and apixaban (Granger et al., 2011; Patel et al., 2011) are currently approved for use in Canada and Europe. The NOACs have rapid onsets and offsets of action, predictable pharmacologic profiles and few food and drug interactions. Compared with warfarin, they have similar efficacy for stroke prophylaxis and a superior safety profile for bleeding risks. One commonly cited reason for an improved NOAC bleeding risk is its reduced risk of intracranial bleeds. However, when the three NOACs are grouped together, the number of patients needed to be treated (NNT) for one patient to suffer an intracranial bleed is between 190 and 469 when compared with warfarin (Gómez-Outes et al., 2013). In addition, these agents are renally cleared, have been shown in some cases to increase gastrointestinal (GI) bleeding (Connolly et al., 2009; Patel et al., 2011) and only dabigatran currently has an approved antidote (Enriquez et al., 2015). NOACs also tend to be more expensive, even when one accounts for the costs of routine monitoring that accompany warfarin. For instance, in the Netherlands, the cost of apixaban over the lifetime of a hypothetical patient $(€ 3870)$ is $~ 10$ times that of warfarin ( $€ 365)$, so that even when accounting for thromboembolic and bleeding complications and costs for routine care and monitoring, apixaban ultimately costs about
$€ 1852$ more (Stevanović et al., 2014). The latest Canadian Cardiovascular Society (CCS) guidelines recommend OAC use in patients with nonvalvular AF aged $\geqslant 65$, with a preference for the use of NOACs over warfarin in most cases (Verma et al., 2014). This recommendation is also consistent with the most recent 2012 guidelines from the European Society of Cardiology (Camm et al., 2012).

For trainees, this evolving landscape can prove to be difficult. We have recently shown that across various specialties, Canadian residents' choices of $\mathrm{OAC}$ for nonvalvular AF differ from the most recent CCS guidelines (Oqab et al., 2015). The primary aim of this sub-study was to examine the choices of Canadian family medicine residents.

\section{Methods}

We used email to distribute a 16-question, webbased, cross-sectional survey of Canadian residency programmes using SurveyMonkey (SurveyMonkey Inc., San Mateo, CA, USA) (Oqab et al., 2015). The questions pertained to resident demographics, assessment of stroke and bleeding risk, and choices of therapy in different clinical scenarios. The clinical scenarios involved the same patient: a 76-year-old male with a past medical history of congestive heart failure and hypertension (congestive heart failure, hypertension, age $\geq 75$, diabetes mellitus, stroke or TIA (2 points) $\left(\mathrm{CHADS}_{2}\right)$ score of 3$)$. We introduced a different comorbidity in each subsequent scenario: a GI bleed on acetylsalicylic acid (ASA) one year ago; an intracranial bleed one year previous; stable stage 3 chronic kidney disease (CKD, estimated glomerular filtration rate (eGFR) $30-59 \mathrm{~mL} / \mathrm{min} / 1.73 \mathrm{~m}^{2}$ ); labile international normalized ratios (INRs) on warfarin; and GI bleeding while on an NOAC. The answer key choices were as follows: no anticoagulation, ASA, warfarin, dabigatran, rivaroxaban, apixaban and don't know. Respondents were permitted to select whichever agent(s) they would recommend to that patient. The study protocol was approved by the Research Ethics Board of Queen's University. See Appendix for the complete survey.

\section{Statistics}

We exported data collected from the SurveyMonkey system to Excel (Microsoft, Redmond, WA, USA), then imported this into IBM SPSS 


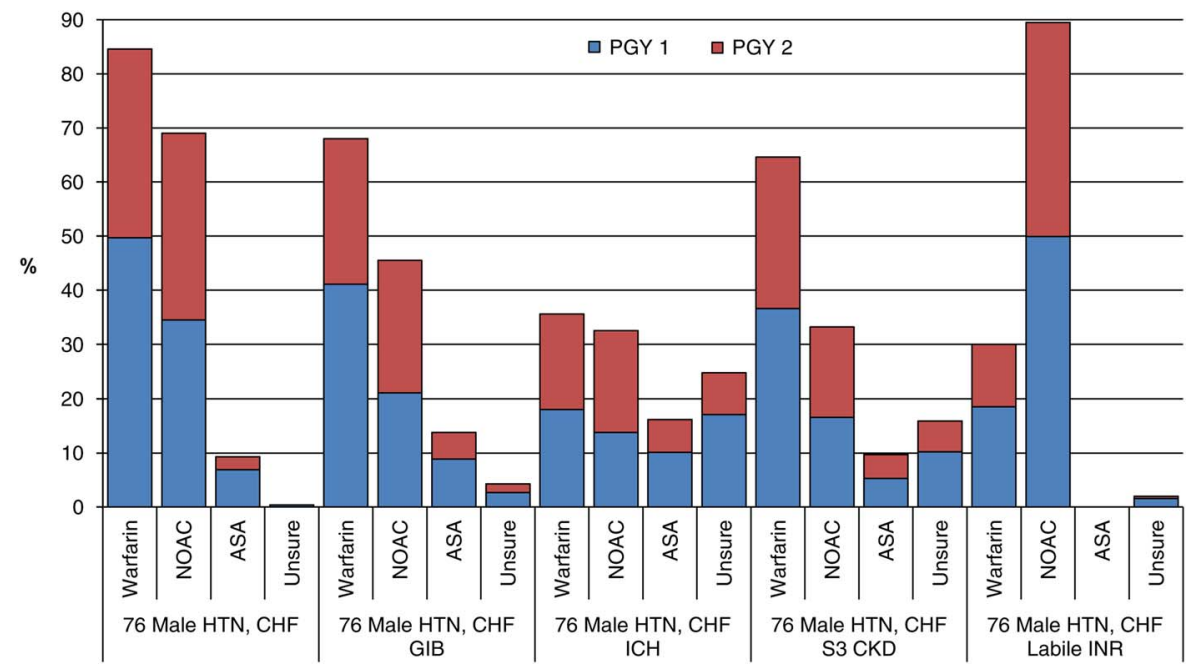

Figure 1 Antithrombotic choices for each clinical scenario by PGY level. Each bar represents the total percentage of residents choosing that option, subdivided into the relative proportion of PGY-1 and PGY-2. NOAC $=$ novel oral anticoagulant; ASA = acetylsalicylic acid; $\mathrm{HTN}=$ hypertension; $\mathrm{CHF}=$ congestive heart failure; GIB = gastrointestinal bleed; $\mathrm{ICH}=$ intracranial haemorrhage; $\mathrm{S} 3 \mathrm{CKD}=$ stable stage 3 chronic kidney disease; INR = international normalized ratio; PGY = postgraduate year.

(version 22.0 for Windows, Armonk, NY, USA) for statistical analysis. We analysed the cumulative descriptive data (frequencies and percentages) for all family medicine residents across the different institutions.

\section{Results}

Residents from different universities participated in the survey. There were 247 total respondents (University of Ottawa, $n=42$; Queen's University, $n=43$; University of Toronto, $n=107$; and University of Manitoba, $n=55$ ). The residents were either at a postgraduate year (PGY)-1 or PGY-2 level. The overall response rate was $32 \%$. The results of this survey are accurate at the $95 \%$ confidence level \pm 3 percentage points.

\section{Experience with OAC}

When residents were asked how many patients they had started on OAC in the last three months, most chose one to five $(66 \%)$, followed by zero $(29 \%)$, six to ten $(5 \%)$ and $\geqslant 11(0.7 \%)$.

When asked about how comfortable residents felt starting OAC, the majority (51\%) felt somewhat comfortable, $21 \%$ felt somewhat uncomfortable, $18 \%$ felt neutral, $7 \%$ felt very comfortable and $3 \%$ felt very uncomfortable.

\section{Clinical stroke risk stratification and bleeding risk assessment}

When asked what tools residents used when deciding on stroke prophylaxis, $\mathrm{CHADS}_{2}$ and congestive heart failure, hypertension, age $\geq 75$ ( 2 points) or age 65-74 (1 point), diabetes mellitus, stroke or TIA, vascular disease including peripheral arterial disease, myocardial infarction, or aortic plaque, sex (female) were chosen by 81 and 67\%, respectively. Residents mostly chose the hypertension, abnormal liver or renal function, stroke, bleeding, labile international normalized ratio, elderly (age $\geq 65$ ), drugs or alcohol score $(84 \%)$ for bleeding risk assessment.

\section{Clinical scenarios}

Residents favoured warfarin over NOACs in an uncomplicated patient with a $\mathrm{CHADS}_{2}$ score of 3 , as well as when the scenario included a history of GI bleeding on ASA, intracranial haemorrhage or stage 3 CKD. A labile INR was the only situation where residents tended to favour NOACs. 
Table 1 Frequency of resident choices of agents for stroke prevention in different clinical scenarios

\begin{tabular}{|c|c|c|c|c|c|c|c|c|c|}
\hline \multirow[t]{2}{*}{ Clinical scenario } & \multirow[t]{2}{*}{ OAC } & \multicolumn{3}{|c|}{ Preferred choices when multiple options selected } & \multicolumn{5}{|c|}{ Preferred choice when a single option selected } \\
\hline & & Warfarin $(n)$ & $\operatorname{NOAC}(n)$ & $\operatorname{ASA}(n)$ & Warfarin $(n)$ & $\operatorname{NOAC}(n)$ & $\operatorname{ASA}(n)$ & None $(n)$ & Unsure $(n)$ \\
\hline $\begin{array}{l}76 \text { Male } \\
\text { CHF, HTN }\end{array}$ & $97.6 \%$ & $84.6 \%(209)$ & $68.3 \%(168)$ & $9.3 \%(23)$ & $27.6 \%(68)$ & $13.4 \%(33)$ & $0.8 \%(2)$ & $1.2 \%(3)$ & $0.4 \%(1)$ \\
\hline $\begin{array}{l}76 \text { Male } \\
\text { CHF, HTN } \\
\text { Hx GIB }\end{array}$ & $88.2 \%$ & $68.0 \%(168)$ & $45.5 \%(112)$ & $13.8 \%(34)$ & $39.4 \%(97)$ & $18.7 \%(46)$ & $6.1 \%(15)$ & $1.2 \%(3)$ & $4.5 \%(11)$ \\
\hline $\begin{array}{l}76 \text { Male } \\
\text { CHF, HTN } \\
\mathrm{Hx} \mathrm{ICH}\end{array}$ & $55.6 \%$ & $35.6 \%(88)$ & $32.5 \%{ }^{a}(80)$ & $16.2 \%(40)$ & $20.3 \%(50)$ & $18.3 \%^{\mathrm{a}}(45)$ & $9.8 \%(24)$ & $9.8 \%(24)$ & $24.8 \%(61)$ \\
\hline $\begin{array}{l}76 \text { Male } \\
\text { CHF, HTN } \\
\text { S3 CKD }\end{array}$ & $79.1 \%$ & $64.8 \%(160)$ & $33.2 \%^{\mathrm{b}}(82)$ & $9.7 \%(24)$ & $42.3 \%(104)$ & $13.8 \% \%^{b}(34)$ & $4.1 \%(10)$ & $0.8 \%(2)$ & $16.0 \%(39)$ \\
\hline $\begin{array}{l}76 \text { Male } \\
\text { CHF, HTN } \\
\text { Labile INR }\end{array}$ & $96.8 \%$ & $30.0 \%(74)$ & $89.4 \%$ (219) & $\mathrm{N} / \mathrm{A}$ & $8.2 \%(20)$ & $67.3 \%(165)$ & $\mathrm{N} / \mathrm{A}$ & $1.2 \%(3)$ & $2.0 \%(5)$ \\
\hline \multicolumn{10}{|c|}{ 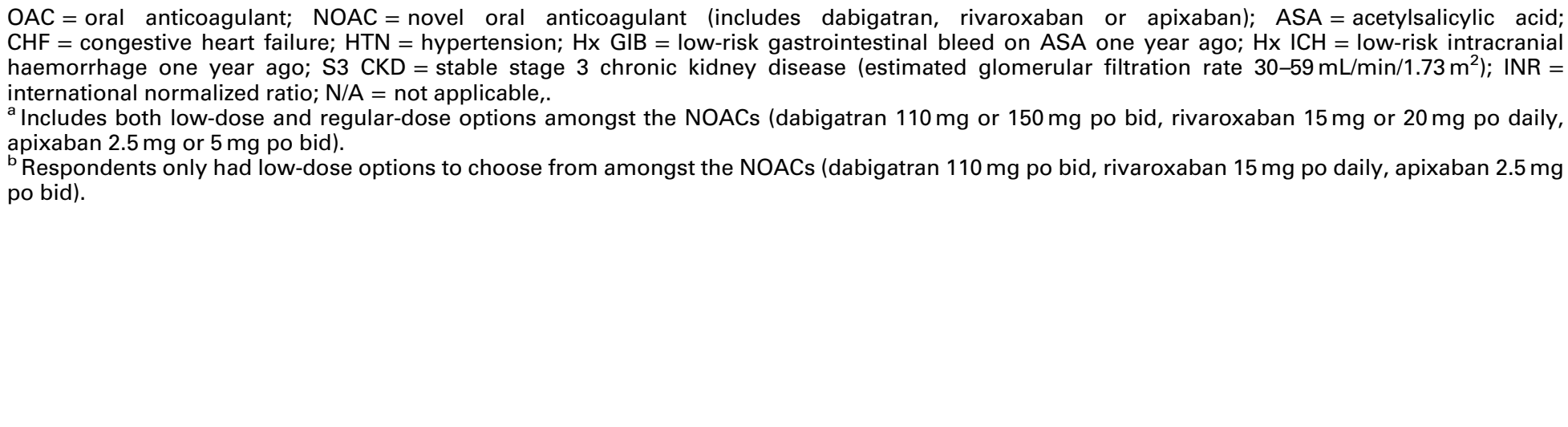 } \\
\hline
\end{tabular}


In addition, a GI bleed while on an NOAC led $34 \%$ of residents to switch to warfarin, while $22 \%$ restarted the NOAC at the same dose, $18 \%$ lowered the NOAC dose and $11 \%$ switched to a different NOAC. Throughout the scenarios, up to a quarter of residents were unsure of their next step. Trends were consistent in both years of training (Figure 1). See Table 1 for a summary of resident antithrombotic choices in five clinical scenarios.

When asked to consider a situation where reversal agents were available for all of NOACs, $65 \%$ of residents indicated that they would no longer prescribe warfarin for the vast majority of their patients, while $16 \%$ were neutral and $19 \%$ disagreed.

When asked to rank what characteristics would be most ( 5 points) to least (1 point) important when considering $\mathrm{OAC}$, on average, they ranked the risk of adverse events (4.2 points), the convenience to the patient (3.6 points), personal familiarity (3.4 points), the availability of a reversal agent (3.4) and then the cost to the patient (3.3 points).

\section{Discussion}

This study is, to the best of our knowledge, the first to explore the contemporary issue of family medicine resident attitudes and choices of OAC for patients with nonvalvular AF. Although the majority of residents chose to appropriately use OAC in our clinical scenarios (56-98\%), the choices of OAC generally were not in keeping with the latest guideline recommendations. These findings are similar to other Canadian residents, including internal medicine, emergency medicine and adult cardiology trainees as well as to the overall prescribing practice of Canadian family physicians (Oqab et al., 2015; Weitz et al., 2015; McIntyre et al., 2016).

Although we found that most family medicine residents prescribe OACs, many admitted their lack of comfort in doing so. In our clinical scenarios, an NOAC would be the preferred treatment according to the CCS guidelines. However, most residents tended to gravitate towards warfarin, regardless of training level. In our sample, almost $85 \%$ of residents considered warfarin in a new uncomplicated diagnosis of nonvalvular AF, while only about $13 \%$ chose to exclusively use an NOAC.
We found that most family medicine residents ranked the risk of adverse events as their top consideration when prescribing OAC. It has been shown that physicians may be more averse to bleeding while patients are more averse to stroke when making prophylaxis decisions in AF (Devereaux et al., 2001). This underscores the importance of incorporating patient values and preferences in shared decision-making (Alonso-Coello et al., 2014). In addition, residents may be placing an unjustified amount of weight on the risk of adverse bleeding events. Although studies and pharmaceutical industries emphasize a statistically significant preference for NOACs with respect to fatal and intracranial bleeding, when one considers baseline risks, absolute risk reductions and NNTs, such risks may be at times exaggerated and overvalued.

Over one-third of our surveyed residents chose warfarin in the setting of an intracranial bleed that occurred a year earlier and was deemed low risk to re-bleed. About $18 \%$ chose to use an NOAC exclusively and about $25 \%$ were uncertain of their next step. However, in the pivotal NOAC trials, rates of intracranial bleeding were significantly less frequent with NOACs compared with warfarin (NNT of 100 for dabigatran $110 \mathrm{mg}$ and 117 for dabigatran $150 \mathrm{mg}$; NNT of 247 for rivaroxaban; NNT of 129 for apixaban) (Connolly et al., 2009; Granger et al., 2011; Patel et al., 2011). Therefore there may be a significant knowledge gap, as the evidence is more compelling pertaining to intracranial bleeding.

Two-thirds of residents favoured warfarin in the setting of a remote low-risk GI bleed, with no major preference towards apixaban, an agent shown to have a trend towards less GI bleeds in its randomized clinical trial (NNT of 628) (Granger et al., 2011). In addition, when faced with a GI bleed while on an NOAC, $22 \%$ opted to continue the NOAC at the same dose, $11 \%$ switched to a different NOAC and $15 \%$ were uncertain of their next step. The literature for other types of bleeding, including GI bleeds, is more disparate and the residents' responses may reflect not only a knowledge gap, but a more confounded evidence base. In the pivotal NOAC trials, while the rates major or clinically relevant non-major bleeding were less frequent with apixaban (NNT of 34) (Granger et al., 2011), the rates of GI bleeding were higher than warfarin with dabigatran $150 \mathrm{mg}$ dose (NNT 
of 100) (Connolly et al., 2009) and rivaroxaban (NNT of 101) (Patel et al., 2011). Overall, the shift in guideline recommendations is due to the current weight of evidence in favour of NOACs, with a favourable risk-benefit profile and statistically significant reductions in stroke, intracranial haemorrhage and mortality compared with warfarin (Ruff et al., 2014). In addition, it would be clinically prudent to consider absolute risks and NNTs in the discussion of risks and benefits with patients during the shared decision-making process.

Residents still tended to favour warfarin (65\%) over a low-dose NOAC exclusively (14\%) in the setting of stable stage 3 CKD (eGFR $30-59 \mathrm{~mL} /$ $\min / 1.73 \mathrm{~m}^{2}$ ). Although up to $80 \%$ of circulating dabigatran, $33 \%$ of rivaroxaban and $25 \%$ of apixaban are excreted renally (Gong and Kim, 2013), society guidelines tend to prefer NOACs in this situation. For instance, CCS recommends that patients with moderate renal impairment (eGFR $30-50 \mathrm{~mL} / \mathrm{min} / 1.73 \mathrm{~m}^{2}$ ) should receive NOACs with dose adjustment (Verma et al., 2014).

When faced with a labile INR on warfarin, about one-third of residents opted to continue warfarin and provide education. Two-thirds were willing to switch to an NOAC exclusively with no major preference for one over the other. Overall, this proportion seems low in light of a significant advantage of NOACs in this regard. Given that quality of life is an important consideration for patients, and that up to $85 \%$ of patients want to actively participate in decisions regarding OAC (Palacio et al., 2015), we wonder how extensively residents factored patients' values and preferences, despite ranking patient convenience as second-most important to their decision-making.

One widely perceived potential disadvantage of NOACs is the absence of an antidote or to rapidly reverse its anticoagulant effects. In fact, almost two-thirds of surveyed residents strongly or somewhat agreed that they would no longer prescribe warfarin for the vast majority of patients should antidotes become universally available. Idarucizumab was recently approved by the United States' Food and Drug Administration for the reversal of dabigatran (Pollack et al., 2015) and factor Xa reversal agents are currently undergoing investigation (Lu et al., 2013). However, despite the accepted ability to reverse warfarin with prothrombin complex concentrates, mortality and morbidity rates following its use in intracranial haemorrhage remain high (Dowlatshahi et al., 2012). Therefore one may argue that for any catastrophic or life-threatening bleed, the ability to reverse an anticoagulant's effects would be inconsequential as outcomes would be poor anyway, and basing the initial choice of therapy on the availability of an antidote is thus of low value.

Poor uptake of CCS AF guidelines by Canadian family medicine practitioners was previously documented after the 2012 CCS guidelines were released (Valentinis et al., 2014). In addition, a contemporary analysis showed that warfarin still represents $\sim 80 \%$ of all OAC prescriptions written by family practitioners, and that the uptake in prescribing of the NOACs has been more gradual for family physicians as compared with cardiologists and neurologists (Weitz et al., 2015). More initiatives aimed at knowledge translation (KT) may help to close the care gap through direct educational efforts (Modig et al., 2012), KT framework that target patients, practice, interdisciplinary teams and local health systems (Haaland et al., 2009; Licskai et al., 2012), practice outreach facilitation focused on quality improvement (Liddy et al., 2011) and evidence-based clinical decision support incorporated into electronic medical records (Koopman et al., 2011; McLaughlin et al., 2013).

\section{Limitations}

Our study has limitations. Our sample size was small, with 247 respondents. However, this is a large number for resident-based surveys, has national representation and is accurate at the $95 \%$ confidence level \pm 3 percentage points. Moreover, the results were similar to those from trainees in other disciplines. As with any survey-based study, data are self-reported and may not be generalizable to what occurs in practice.

\section{Conclusions}

There is discordance between Canadian family medicine residents' attitudes and choices of OAC in nonvalvular AF and the most recent Canadian and European guidelines. Although the majority of residents appropriately chose to anticoagulate patients, there was a general hesitancy to prescribe an NOAC over warfarin, likely due to a sometimes 
amplified fear of adverse bleeding events and a knowledge gap in the setting of an evolving body of evidence.

\section{Acknowledgements}

None.

\section{Financial Support}

This article was supported by an unrestricted grant from Bayer HealthCare Canada.

\section{Conflicts of Interest}

None.

\section{References}

Albers, G.W., Amarenco, P., Easton, J.D., Sacco, R.L. and Teal, P. 2004: Antithrombotic and thrombolytic therapy for ischemic stroke: the Seventh ACCP Conference on Antithrombotic and Thrombolytic Therapy. Chest 126, 483S-512S.

Alonso-Coello, P., Montori, V.M., Diaz, M.G., Devereaux, P.J., Mas, G., Diez, A.I., Sola, I., Roura, M., Souto, J.C., Oliver, S., Ruiz, R., Coll-Vinent, B., Gich, I., Schunemann, H.J. and Guyatt, G. 2014: Values and preferences for oral antithrombotic therapy in patients with atrial fibrillation: physician and patient perspectives. Health Expectations: An International Journal of Public Participation in Health Care and Health Policy 18, 2318-327.

Andrade, J., Khairy, P., Dobrev, D. and Nattel, S. 2014: The clinical profile and pathophysiology of atrial fibrillation: relationships among clinical features, epidemiology, and mechanisms. Circulation Research 114, 1453-468.

Camm, A.J., Lip, G.Y., De Caterina, R., Savelieva, I., Atar, D., Hohnloser, S.H., Hindricks, G., Kirchhof, P., and ESC Committee for Practice Guidelines (CPG). 2012: 2012 focused update of the ESC Guidelines for the management of atrial fibrillation: an update of the 2010 ESC Guidelines for the management of atrial fibrillation. Developed with the special contribution of the European Heart Rhythm Association. European Heart Journal 33, 2719-747.

Connolly, S.J., Ezekowitz, M.D., Yusuf, S., Eikelboom, J., Oldgren, J., Parekh, A., Pogue, J., Reilly, P.A., Themeles, E., Varrone, J., Wang, S., Alings, M., Xavier, D., Zhu, J., Diaz, R., Lewis, B.S., Darius, H., Diener, H.C., Joyner, C.D., Wallentin, L., and RE-LY Steering Committee and Investigators. 2009: Dabigatran versus warfarin in patients with atrial fibrillation. The New England Journal of Medicine 361, 1139-151.

Primary Health Care Research \& Development 2017; 18: 472-481
Devereaux, P.J., Anderson, D.R., Gardner, M.J., Putnam, W., Flowerdew, G.J., Brownell, B.F., Nagpal, S. and Cox, J.L. 2001: Differences between perspectives of physicians and patients on anticoagulation in patients with atrial fibrillation: observational study. British Medical Journal (Clinical Research Edition) 323, 1218-222.

Dowlatshahi, D., Butcher, K.S., Asdaghi, N., Nahirniak, S., Bernbaum, M.L., Giulivi, A., Wasserman, J.K., Poon, M.C., Coutts, S.B., and Canadian PCC Registry (CanPro) Investigators. 2012: Poor prognosis in warfarin-associated intracranial hemorrhage despite anticoagulation reversal. Stroke 43, 1812-817.

Enriquez, A., Lip, G.Y. and Baranchuk, A. 2015: Anticoagulation reversal in the era of the non-vitamin $\mathrm{K}$ oral anticoagulants. Europace 18, 955-64.

Go, A.S., Hylek, E.M., Phillips, K.A., Chang, Y., Henault, L.E., Selby, J.V. and Singer, D.E. 2001: Prevalence of diagnosed atrial fibrillation in adults: national implications for rhythm management and stroke prevention: the AnTicoagulation and Risk Factors in Atrial Fibrillation (ATRIA) Study. The Journal of the American Medical Association 285, 2370-375.

Gómez-Outes, A., Terleira-Fernández, A.I., Calvo-Rojas, G., Suárez-Gea, M.L. and Vargas-Castrillón, E. 2013: Dabigatran, rivaroxaban, or apixaban versus warfarin in patients with nonvalvular atrial fibrillation: a systematic review and meta-analysis of subgroups. Thrombosis 2013, 640723.

Gong, I.Y. and Kim, R.B. 2013: Importance of pharmacokinetic profile and variability as determinants of dose and response to dabigatran, rivaroxaban, and apixaban. The Canadian Journal of Cardiology 29, S24-33.

Granger, C.B., Alexander, J.H., McMurray, J.J., Lopes, R.D., Hylek, E.M., Hanna, M., Al-Khalidi, H.R., Ansell, J., Atar, D., Avezum, A., Bahit, M.C., Diaz, R., Easton, J.D., Ezekowitz, J.A., Flaker, G., Garcia, D., Geraldes, M., Gersh, B.J., Golitsyn, S., Goto, S., Hermosillo, A.G., Hohnloser, S.H., Horowitz, J., Mohan, P., Jansky, P., Lewis, B.S., Lopez-Sendon, J.L., Pais, P., Parkhomenko, A., Verheugt, F.W., Zhu, J., Wallentin, L., and ARISTOTLE Committees and Investigators. 2011: Apixaban versus warfarin in patients with atrial fibrillation. The New England Journal of Medicine 365, 981-92.

Haaland, D.A., Cohen, D.R., Kennedy, C.C., Khalidi, N.A., Adachi, J.D. and Papaioannou, A. 2009: Closing the osteoporosis care gap: increased osteoporosis awareness among geriatrics and rehabilitation teams. BioMed Central Geriatrics 9, 28.

Hart, R.G., Pearce, L.A. and Aguilar, M.I. 2007: Meta-analysis: antithrombotic therapy to prevent stroke in patients who have nonvalvular atrial fibrillation. Annals of Internal Medicine 146, 857-67.

Jones, M., McEwan, P., Morgan, C.L., Peters, J.R., Goodfellow, J. and Currie, C.J. 2005: Evaluation of the pattern of treatment, level of anticoagulation control, and outcome of treatment with warfarin in patients with nonvalvar atrial fibrillation: a record linkage study in a large British population. Heart 91, 472-77. 
King, D.E., Dickerson, L.M. and Sack, J.L. 2002: Acute management of atrial fibrillation: Part II. Prevention of thromboembolic complications. American Family Physician 66, 261-64.

Koopman, R.J., Kochendorfer, K.M., Moore, J.L., Mehr, D.R., Wakefield, D.S., Yadamsuren, B., Coberly, J.S., Kruse, R.L., Wakefield, B.J. and Belden, J.L. 2011: A diabetes dashboard and physician efficiency and accuracy in accessing data needed for high-quality diabetes care. Annals of Family Medicine 9, 398-405.

Licskai, C., Sands, T., Ong, M., Paolatto, L. and Nicoletti, I. 2012: Using a knowledge translation framework to implement asthma clinical practice guidelines in primary care. International Journal for Quality in Health Care 24, $538-46$.

Liddy, C., Hogg, W., Russell, G., Wells, G., Armstrong, C.D., Akbari, A., Dahrouge, S., Taljaard, M., Mayo-Bruinsma, L., Singh, J. and Cornett, A. 2011: Improved delivery of cardiovascular care (IDOCC) through outreach facilitation: study protocol and implementation details of a cluster randomized controlled trial in primary care. Implementation Science 6, 110.

Lu, G., DeGuzman, F.R., Hollenbach, S.J., Karbarz, M.J., Abe, K., Lee, G., Luan, P., Hutchaleelaha, A., Inagaki, M., Conley, P.B., Phillips, D.R. and Sinha, U. 2013: A specific antidote for reversal of anticoagulation by direct and indirect inhibitors of coagulation factor Xa. Nature Medicine 19, 446-51.

McIntyre, W., Oqab, Z., Yazdan-Ashoori, P., Quinn, K., van Oosten, E., Hopman, W. and Baranchuk, A. 2016: Stroke prevention for patients with nonvalvular atrial fibrillation: values and preferences of Canadian emergency medicine trainees. American Journal of Emergency Medicine 34, 1685-687.

McLaughlin, V.V., Langer, A., Tan, M., Clements, P.J., Oudiz, R.J., Tapson, V.F., Channick, R.N. and Rubin, L.J., Pulmonary Arterial Hypertension-Quality Enhancement Research Initiative. 2013: Contemporary trends in the diagnosis and management of pulmonary arterial hypertension: an initiative to close the care gap. Chest 143, 324-32.

Modig, S., Hoglund, P., Troein, M. and Midlov, P. 2012: GP's adherence to guidelines for cardiovascular disease among elderly: a quality development study. The Scientific World Journal 2012, 767892.

Oqab, Z., McIntyre, W.F., Quinn, K.L., Lamb, T., Quadros, K., Yazdan-Ashoori, P., van Oosten, E., Chu, K., Lamba, J., Barake, W., Mohajer, K., Marr, J.N. and Baranchuk, A. 2015: Resident physicians choices of anticoagulation for stroke prevention in patients with nonvalvular atrial fibrillation. The Canadian Journal of Cardiology 32, 824-28.

Palacio, A.M., Kirolos, I. and Tamariz, L. 2015: Patient values and preferences when choosing anticoagulants. Patient Preference and Adherence 9, 133-38.

Patel, M.R., Mahaffey, K.W., Garg, J., Pan, G., Singer, D.E., Hacke, W., Breithardt, G., Halperin, J.L., Hankey, G.J., Piccini, J.P., Becker, R.C., Nessel, C.C., Paolini, J.F.,
Berkowitz, S.D., Fox, K.A. and Califf, R.M., ROCKET AF Investigators. 2011: Rivaroxaban versus warfarin in nonvalvular atrial fibrillation. The New England Journal of Medicine 365, 883-91.

Pirmohamed, M., James, S., Meakin, S., Green, C., Scott, A.K., Walley, T.J., Farrar, K., Park, B.K. and Breckenridge, A.M. 2004: Adverse drug reactions as cause of admission to hospital: prospective analysis of 18820 patients. British Medical Journal (Clinical Research Edition) 329, 15-19.

Pollack, C.V. Jr, Reilly, P.A., Eikelboom, J., Glund, S., Verhamme, P., Bernstein, R.A., Dubiel, R., Huisman, M.V., Hylek, E.M., Kamphuisen, P.W., Kreuzer, J., Levy, J.H., Sellke, F.W., Stangier, J., Steiner, T., Wang, B., Kam, C.W. and Weitz, J.I. 2015: Idarucizumab for dabigatran reversal. The New England Journal of Medicine 373, 511-20.

Ruff, C.T., Giugliano, R.P., Braunwald, E., Hoffman, E.B., Deenadayalu, N., Ezekowitz, M.D., Camm, A.J., Weitz, J.I., Lewis, B.S., Parkhomenko, A., Yamashita, T. and Antman, E.M. 2014: Comparison of the efficacy and safety of new oral anticoagulants with warfarin in patients with atrial fibrillation: a meta-analysis of randomised trials. Lancet 383, 955-62.

Stevanović, J., Pompen, M., Le, H.H., Rozenbaum, M.H., Tieleman, R.G. and Postma, M.J. 2014: Economic evaluation of apixaban for the prevention of stroke in nonvalvular atrial fibrillation in the Netherlands. PLoS One 9, e103974.

Valentinis, A., Ivers, N., Bhatia, S., Meshkat, N., Leblanc, K., Ha, A. and Morra, D. 2014: Atrial fibrillation anticoagulation care in a large urban family medicine practice. Canadian Family Physician 60, e173-179.

Verma, A., Cairns, J.A., Mitchell, L.B., Macle, L., Stiell, I.G., Gladstone, D., McMurtry, M.S., Connolly, S., Cox, J.L., Dorian, P., Ivers, N., Leblanc, K., Nattel, S., Healey, J.S., and CCS Atrial Fibrillation Guidelines Committee. 2014: 2014 focused update of the Canadian Cardiovascular Society Guidelines for the management of atrial fibrillation. The Canadian Journal of Cardiology 30, 1114-130.

Weitz, J.I., Semchuk, W., Turpie, A.G., Fisher, W.D., Kong, C., Ciaccia, A. and Cairns, J.A. 2015: Trends in prescribing oral anticoagulants in Canada, 2008-2014. Clinical Therapeutics 37, 2506-514.

Wells, P.S., Holbrook, A.M., Crowther, N.R. and Hirsh, J. 1994: Interactions of warfarin with drugs and food. Annals of Internal Medicine 121, 676-83.

\section{Appendix}

\section{Demographics}

Email Address (optional)

Residency Center

PGY level 
Program
a) Family Medicine
b) Emergency Medicine
c) Internal Medicine
d) Adult Cardiology

\section{Anticoagulation and Bleeding risk}

1. How many patients have you started on an oral anticoagulant in the last 3 months (whether independently or with the help of a senior resident or an attending physician)? (Choose one)
a) 0
b) $1-5$
c) $6-10$
d) $>11$

2. When assessing the need for anticoagulation for stroke prevention for a patient with nonvalvular atrial fibrillation, which stroke risk prediction score do you use? (Choose all that apply)
a) $\mathrm{CHADS} 2$
b) CHA2DS2-VASc
c) AFI (Atrial Fibrillation Investigators)
d) SPAF III (Stroke Prevention in Atrial Fibrillation)
e) Don't know

3. What schema do you use to determine the risk of bleeding for a patient you have determined requires an oral anticoagulant? (Choose all that apply)
a) HAS-BLED
b) HEMOR2RAGES
c) ATRIA
d) Clinical impression
e) Don't know

\section{Clinical scenarios}

1. A 76 year-old male with newly diagnosed atrial fibrillation with CHADS2 score of 3 (past medical history of congestive heart failure and hypertension), what do you suggest to your patient? (Choose all that apply)
a) No anticoagulation
b) ASA
c) Warfarin (Coumadin) adjusted to an INR 2.0-3.0
d) Dabigatran
e) Rivaroxaban
f) Apixaban
g) Don't know

Primary Health Care Research \& Development 2017; 18: 472-481
2. A 76-year-old male with newly diagnosed atrial fibrillation with CHADS2 score of 3 (past medical history of congestive heart failure and hypertension) and previous upper GI bleed from an ulcer 1 year ago while on ASA which did not require transfusion and was deemed by the GI specialist to be low-risk to re-bleed, what do you suggest to your patient? (Choose all that apply)
a) No anticoagulation
b) ASA
c) Warfarin (Coumadin) adjusted to an INR 2.0-3.0
d) Dabigatran
e) Rivaroxaban
f) Apixaban
g) Don't know

3. A 76-year-old male with newly diagnosed atrial fibrillation with CHADS2 score of 3 (past medical history of congestive heart failure and hypertension) and previous intracranial bleed 1 year ago and was deemed by a neurosurgical specialist to be low-risk to re-bleed, what do you suggest to your patient? (Choose all that apply)
a) No anticoagulation
b) ASA
c) Warfarin (Coumadin) adjusted to an INR 2.0-3.0
d) Dabigatran $150 \mathrm{mg}$ twice daily
e) Dabigatran $110 \mathrm{mg}$ twice daily
f) Rivaroxaban $20 \mathrm{mg}$ once daily
g) Rivaroxaban $15 \mathrm{mg}$ once daily
h) Apixaban $5 \mathrm{mg}$ twice daily
i) Apixaban $2.5 \mathrm{mg}$ twice daily
j) Don't know

4. A 76-year-old male with newly diagnosed atrial fibrillation with CHADS2 score of 3 (past medical history of congestive heart failure and hypertension) with stable Stage 3 chronic kidney disease (eGFR of $30-59 \mathrm{ml} / \mathrm{min} / 1.73 \mathrm{~m}^{2}$ ), what do you suggest to your patient? (Choose all that apply)
a) No anticoagulation
b) Aspirin
c) Warfarin (Coumadin) adjusted to an INR 2.0-3.0
d) Dabigatran $110 \mathrm{mg}$ twice daily
e) Rivaroxaban $15 \mathrm{mg}$ once daily
f) Apixaban $2.5 \mathrm{mg}$ twice daily
g) Don't know 
5. You are a resident in a clinic seeing a 76 yearold gentleman who has atrial fibrillation with CHADS2 score of 3 (past medical history of congestive heart failure and hypertension) and is currently on warfarin. He has no history of prior bleeding events while on anticoagulation and has normal kidney function. You are having difficulty adjusting his dose of warfarin to keep him within the therapeutic range due to missed blood-work appointments. What do you recommend for your patient? (Choose all that apply)

a) Continue warfarin and provide education to patient

b) Switch patient to dabigatran

c) Switch patient to rivaroxaban

d) Switch patient to apixaban

e) Stop all anticoagulation

f) Don't know

6. Mr. Smith is 76 years old with atrial fibrillation and a CHADS2 score of 3 (past medical history of congestive heart failure and hypertension) who presents to the ER with an upper GI bleed while on a new oral anticoagulant. Gastroenterology treated him and deemed him a low re-bleed risk and recommended it is safe to resume anticoagulation if the risk of stroke is high. What do you suggest to your patient? (Choose one)

a) Restart previous new oral anticoagulant at the same dose

b) Restart previous new oral anticoagulant with a lower dose

c) Switch to a different new oral anticoagulant

d) Switch patient to warfarin adjusted to an INR 2.0-3.0

f) Stop all anticoagulation indefinitely

g) Don't know

\section{Miscellaneous}

7. Mr. Smith is 76 years old with a new diagnosis of atrial fibrillation with a CHADS2 score of 3 (past medical history of congestive heart failure and hypertension) requiring anticoagulation prior to discharge home from the emergency department. Who do you think should prescribe oral anticoagulation for this patient? (Choose one)
a) Emergency Department physician
b) Family physician
c) Consult to Cardiology service
d) Consult to Internal Medicine
e) Don't know

8. How much do you agree with the following statement: When a reversal agent becomes available for one of the 'novel' oral anticoagulants, I will no longer prescribe warfarin for stroke prevention in the vast majority of my patients with nonvalvular atrial fibrillation. (Choose one)
a) Strongly disagree
b) Somewhat disagree
c) Neither agree nor disagree
d) Somewhat Agree
e) Strongly agree

9. What do you consider most when choosing an oral anticoagulant for your patient?

Please rank the following options, 1 is least important to 5 most important

a) Availability of a reversal agent 12345

b) Risk of adverse events 12345

c) Cost to patient 12345

d) Personal familiarity with the medication 12345

e) Convenience to patient (frequency of daily dosing and need for monitoring)

12345

10. Overall, how comfortable are you with prescribing an oral anticoagulant (including NOAC) to your patient? (Choose one)
a) Very comfortable
b) Somewhat comfortable
c) Neither
d) Somewhat uncomfortable
e) Very uncomfortable 